\title{
SURFACE WETTABILITY OF BRAZILIAN TROPICAL WOOD FLOORING TREATED WITH He PLASMA
}

\author{
Pedro Henrique G. de Cademartori' ${ }^{1}$,Silvana Nisgoski', Washington L. E. Magalhães', \\ Graciela Ines B. de Muniz,
}

\begin{abstract}
This study investigated the effect of plasma treatment on changes of surface wettability of wood flooring from two Brazilian tropical species, Hymenaea spp. (rode locus) and Tabebuia spp. (lapacho). Wood flooring samples were plasma treated at low pressure in a helium atmosphere. Energy level was set at $100 \mathrm{~W}$ and four glow discharge times $(5,15,30$ and $45 \mathrm{~s})$ were tested. Changes in wettability were investigated by measuring apparent contact angle, droplet volume and spreading contact area. The results showed less susceptibility of lapacho wood to the plasma treatments, while reduction of apparent contact angle in rode locus wood reached up to $76 \%$ for longer discharge times. In general, discharge time of $15 \mathrm{~s}$ produced the same effect as discharge of $45 \mathrm{~s}$ on wettability, which is important for industrial applications. Visual analyses revealed increase of water droplet spreading on lapacho wood surface, even though the variation of spreading contact area was not significant. Plasma treatment is feasible to improve wettability of tropical woods. Nevertheless, these findings should be investigated further due to the intrinsic characteristics of woods from tropical species.
\end{abstract} wetting.

Keywords: Contact angle, glow discharge, plasma treatment, spreading, surface modification,

\section{INTRODUCTION}

Wood flooring from tropical species is an important market niche for sale of wood and wood-based products. Brazil is the third leading producer of certified tropical logs - around 30,8 million $\mathrm{m}^{3}$ in 2013-2014 - only behind Indonesia and India, respectively (International Tropical Timber Organization 2015). Among these tropical species, rode locus (Hymenaea spp.) and lapacho (Tabebuia spp.) are widely used as raw materials to make flooring due to their attractiveness, especially related to their high natural durability and hardness. For example, Tabebuia serratifolia is one of the most widely used species for wood flooring in Italy (Romagnoli et al. 2013).

In the manufacturing process, the surface of wood flooring is commonly coated with finishing chemical products to improve various surface properties, such as resistance against weathering and scratching, and hardness. Nevertheless, surface adhesion of coatings can be limited due to intrinsic characteristics and/or surface inactivation of the wood. Wettability of wood surface is one of these characteristics that significantly affects the gluing and/or coating process (Thenepalli et al. 2015), since it is a measure of how fast a liquid spreads, wets or is repelled by a material's surface (Akgül et al. 2012). Furthermore, surface inactivation influences the wettability of wood. This phenomenon of inactivation can occur due to migration of extractives to the wood surface, surface oxidation and/or modification of surface hydroxyl bonding sites (Christiansen 1991). The severity of wood inactivation can be influenced by moisture content, temperature and exposure of the material in the environment (Aydin and Demirkir 2010).

\footnotetext{
${ }^{1}$ Centro de Ciências Florestais e da Madeira (PPGEF), Universidade Federal do Paraná (UFPR), Curitiba, Brazil. pedrocademartori@gmail.com; nisgoski@ufpr.br; gbmunize@ufpr.br

${ }^{2}$ Embrapa Florestas, Estrada da Ribeira, Colombo, Brazil, washington.magalhaes@embrapa.br

•Corresponding author: gbmunize@ufpr.br

Received: 29.03.2016 Accepted: 25.08.2016
} 
Because of these aspects, plasma technology has been used to increase wettability and surface adhesion of wood and wood-based products, reducing or avoiding these problems in the wood/coating interface (Asandulesa et al. 2010; Acda et al. 2012; Avramidis, G. et al. 2012; Tang et al. 2012; Riedl et al. 2014; Cademartori et al. 2015; Novák et al. 2015; Hünnekens et al. 2016). The effect of plasma on wettability of these materials is generated mainly by changes in their chemical structure and surface cleaning process (Dineff et al. 2011), which occur only in the outermost layer of the material's surface (Denes et al. 1999). These chemical changes, and consequently the increase of hydrophilicity, occur by the introduction of new functional groups on the substrate surface and/or by breaking the polymer chains on the outermost layer followed by crosslinking (Liston 1989; Carlotti and Mas 1998; D'agostino et al. 2008).

Experiments are initially necessary to understand the effect of plasma treatment on the surface of solid wood flooring products. This is necessary to extend practical applications, since the effects of plasma on the wood flooring materials have not been thoroughly explored, especially of tropical species with high market potential. In this study, radiofrequency glow discharge in helium (He) was used to improve surface wettability of solid wood flooring from two Brazilian tropical species, rode locus (Hymenaea spp.) and lapacho (Tabebuia spp.). The effect of treatment time on surface wettability was investigated in a low pressure plasma glow discharge. Changes in apparent contact angle (CA), volume of water droplet and spreading contact area (SCA) of droplet were investigated, expanding the existing results to other high-quality woods.

\section{MATERIAL AND METHODS}

\section{Raw material}

Rode locus (Hymenaea spp.) and lapacho (Tabebuia spp.) wood floor tiles measuring $80 \mathrm{x} 27 \mathrm{x}$ $20 \mathrm{~mm}$ (length, width and thickness) were purchased in a local market. These tiles were cut into small pieces of $25 \times 20 \times 20 \mathrm{~mm}$ (radial $\times$ tangential $\times$ longitudinal). Then, the samples were sanded with 120 -grit sandpaper and were kept in a climatic chamber $\left(20^{\circ} \mathrm{C}\right.$ and $65 \%$ relative humidity) to reach the equilibrium moisture content (around 12\%).

\section{Plasma treatments}

Plasma treatments were performed in a homemade cylindrical stainless steel reactor (capacitively coupled plasma) with $50 \mathrm{~cm}$ diameter. This reactor works at low pressure with a radiofrequency power supply. It was previously described in detail by Cademartori et al. (2015).

Before the plasma treatments, $\mathrm{He}(>99 \%$ purity) was inserted inside the chamber at $0,032 \mathrm{~Pa}$ for $180 \mathrm{~s}$ to remove contaminants. Then, glow discharges were performed at $\sim 10,64 \mathrm{~Pa}$ pressure with a $\mathrm{He}$ gas flow of $20 \mathrm{sccm}$. Energy level (power) was set at $100 \mathrm{~W}$ and four discharge times $(5,15,30$ and 45 s) were tested. All untreated and plasma treated samples were kept in a desiccator for $24 \mathrm{~h}$ to avoid the contact with humid air and contaminants until the wettability characterization. Plasma treatments were performed on the tangential wood surface.

\section{Wettability parameters}

Wettability parameters of both untreated and plasma treated wood flooring samples were investigated by the sessile drop contact angle technique in a DataPhysics OCA $15+$ goniometer. Three droplets of distilled water with $5 \mu l$ volume were deposited on the tangential surface of each sample. The measurements of CA were performed in the parallel direction to the fibers. Ten samples for each treatment time and each species were used, totaling 100 wood samples. All the CA measurements were performed at the same time in an air conditioned room at $20 \pm 5{ }^{\circ} \mathrm{C}$ and $65 \pm 5 \%$ relative humidity, to avoid external influences. 
The apparent CA and water droplet volume were determined 5, 15, 30, 45 and $60 \mathrm{~s}$ after droplet deposition on the tangential wood flooring surface. High-resolution images were captured $15 \mathrm{~s}$ after droplet deposition using a Zeiss Discovery 1.0 stereomicroscope to determine SCA in $\mathrm{mm}^{2}$ (Cademartori et al. 2015).

\section{Statistical analysis}

The wettability parameters were analyzed by descriptive statics and analysis of variance (ANOVA) at $5 \%$ probability of error. The Durbin-Watson test was used to confirm the normality of data variance. When the null hypothesis was rejected $(p<0,05)$, the average values were compared by the Tukey HSD (Honestly Significant Difference) test at $5 \%$ probability of error.

\section{RESULTS AND DISCUSSION}

Kinetics of apparent CA were investigated as a function of time after droplet deposition to show that distinct behavior of wettability of the Brazilian wood floorings after plasma treatments is not specific to a single measurement point (Figure 1). Apparent CA of plasma treated lapacho wood flooring slightly decreased for all discharge times, especially up to $15 \mathrm{~s}$ after droplet deposition. On the other hand, the reduction of apparent $\mathrm{CA}$ of rode locus wood flooring as a function of time after droplet deposition was more intense than the decrease observed for lapacho wood. Fast penetration and spreading of water droplets were observed, especially in samples submitted to plasma treatments for $15 \mathrm{~s}$ or longer discharge times.
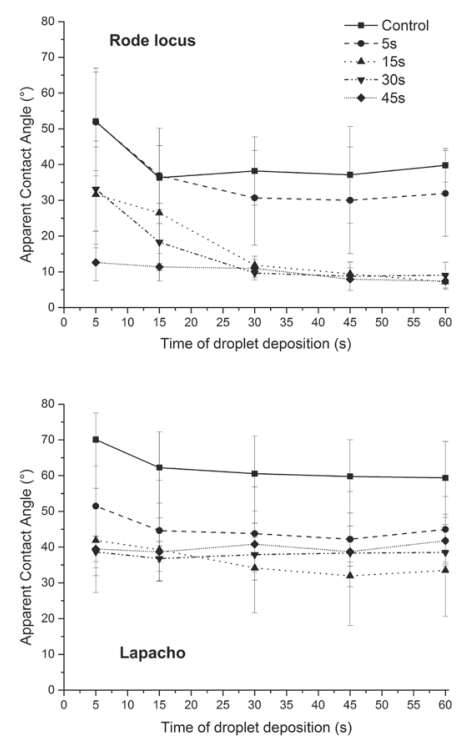

Figure 1. Kinetics of apparent CA of lapacho and rode locus wood flooring as a function of time after droplet deposition.

ANOVA results revealed a significant influence of plasma treatment on both apparent CA and droplet volume of lapacho wood flooring. Regarding rode locus wood flooring, only the apparent CA parameter changed significantly after the plasma treatments (Table 1). Previous studies (Avramidis, G. et al. 2012; Potočňáková et al. 2013; Novák et al. 2015) with wood and wood-based products have also reported this variation of wettability as a function of discharge time. 
Table 1. Summary of analysis of variance (ANOVA) for apparent CA at $5 \mathrm{~s}$, droplet volume at $5 \mathrm{~s}$ and SCA of wood floorings as a function of glow discharge time.

\begin{tabular}{|l|l|l|l|}
\hline \multirow{2}{*}{ Species } & \multirow{2}{*}{ Parameter } & Glow discharge time \\
\cline { 3 - 4 } & & F-ratio & p-value \\
\hline \multirow{3}{*}{ Lapacho } & Apparent CA & $21,14^{*}$ & 0,0000 \\
\cline { 2 - 4 } & Droplet Volume & $4,00^{*}$ & 0,0073 \\
\cline { 2 - 4 } & SCA & $0,83^{\mathrm{ns}}$ & 0,5148 \\
\hline \multirow{3}{*}{ Rode locus } & Apparent CA & $13,28^{*}$ & 0,0000 \\
\cline { 2 - 4 } & Droplet Volume & $2,23^{\mathrm{ns}}$ & 0,0950 \\
\cline { 2 - 4 } & SCA & - & - \\
\hline
\end{tabular}

* Significant at 5\% probability of error. SCA was measured only in lapacho wood flooring because droplets fully spread across the surface of rode locus wood $15 \mathrm{~s}$ after deposition.

In general, apparent CA decreased with increasing discharge time, followed by stabilization (Figure 2). Apparent CA of lapacho wood flooring decreased up to $\sim 44 \%$, while rode locus wood flooring presented the highest reduction $(\sim 76 \%)$. This confirms significant changes in surface free energy of wood floor tiles due to the action of plasma treatments. The active species - such as He metastable, ions, electrons or UV radiation - in a He glow discharge strike the wood surface, causing crosslinking of the molecules. In addition, they decrease the contact angle and increase the surface free energy (Placinta et al. 1997), which was proved in this study for both lapacho and rode locus wood floor tiles. Removal of hydrophobic extractives from the plasma-treated wood surface contributes to increase the surface energy, and consequently to reduce the water contact angle (Avramidis et al. 2012). Moreover, changes in anatomical structure of wood - such as porous modification - by plasma etching result in the opening of liquid penetration paths (Jamali and Evans 2011), which also contributes to increase wood wettability.

Selection of most favorable processing parameters, such as energy levels and discharge times, is interesting due to the possibility to reducing energy cost and processing times (Cademartori et al. 2015). Thus, from an industrial point of view, $15 \mathrm{~s}$ discharge time produces the same effect as $45 \mathrm{~s}$ discharge time in the wettability of both lapacho and rode locus wood floorings. This suggests an increment of surface adhesion of wood flooring, which may improve finishing and bonding steps and decrease processing times in a wood flooring production line.

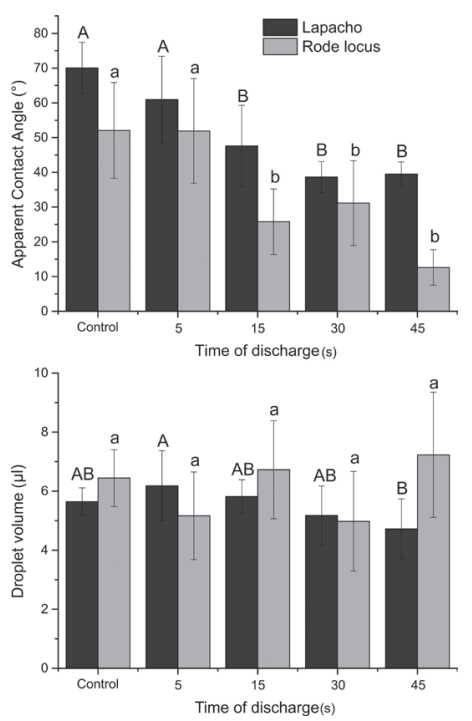

Figure 2. Apparent CA and droplet volume of rode locus and lapacho wood floorings as a function of discharge time. Average values followed by different upper case letters for lapacho wood and lower case letters for rode locus wood are statistically different at $5 \%$ probability of error. 
Water droplet volume significantly changed only in plasma treated lapacho wood flooring (Figure 2). No significant loss in volume means only the occurrence of spreading phenomenon on the surface of rode locus wood flooring. On the other hand, the significant loss of droplet volume in plasma treated lapacho wood flooring suggests (in addition to the spreading phenomenon) a strong influence of both sorption and saturation phenomena in water-surface interaction. Nevertheless, the changes in droplet volume on lapacho wood surface were not systematic as a function of discharge time.

Lapacho wood flooring was less susceptible to plasma treatment in comparison to rode locus, since apparent CA tended to stabilize from $15 \mathrm{~s}$ to $45 \mathrm{~s}$ glow discharge time. This lesser susceptibility of lapacho wood may be related to the plentiful presence of extractives on the surface, especially lapachol, which is one of the most abundant extractives in Tabebuia spp. wood (Romagnoli et al. 2013). This phenolic compound is a naphthoquinone with hydrophobic character and low water solubility, which may have affected the interaction between water droplet and wood surface. Furthermore, the ample presence of extractives facilitates migration of these compounds from bulk to surface of wood, which may reduce the effect of plasma treatment due to the surface inactivation.

SCA of rode locus wood was not measured due to the fast spread of water throughout the surface of the samples. Water droplets spread over the entire surface, which hampered the SCA measurement. Visual and qualitative analyses allowed inferring higher spreading of water droplets on the plasma treated lapacho wood surface as a function of discharge time. Changes in SCA of lapacho wood remained between $\sim 8$ and $\sim 15 \%$ (Figure 3 ), while SCA did not vary statistically after plasma treatments (Table 1). This was expected, since different characteristics influence SCA, such as contact angle, droplet diameter, speed of impact and surface roughness (Chandra et al. 1996; Fujimoto et al. 2001; Kannangara and Shen 2008; Wang et al. 2009).

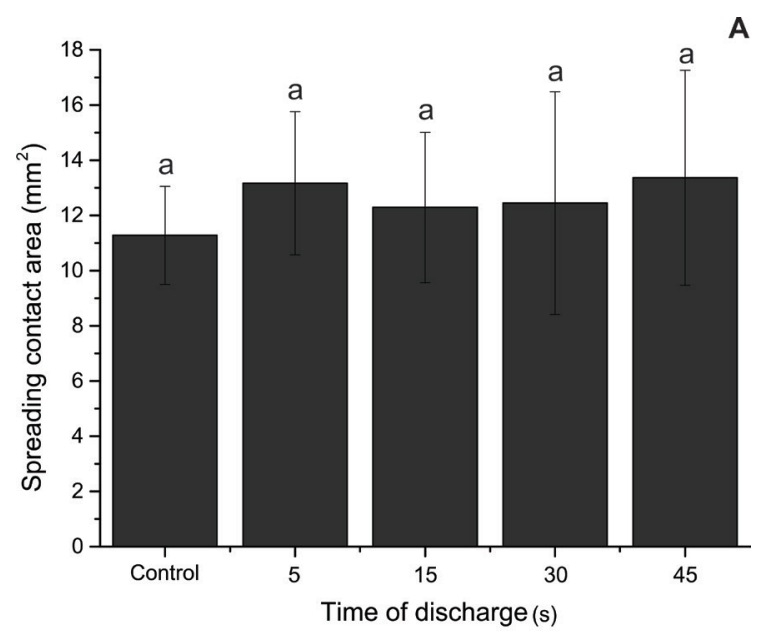

B

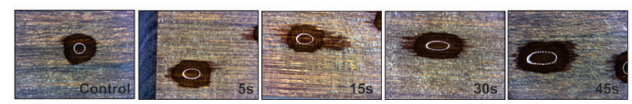

Figure 3. Variation of SCA (A) and plan high-resolution images (B) of lapacho wood flooring as a function of glow discharge time. Average values followed by different lower case letters are statistically different at $5 \%$ probability of error.

From an industrial processing standpoint, the experimental observations in the present paper confirm the feasibility of applying plasma treatment to improve wettability of tropical wood flooring surfaces, and consequently can help to improve the quality of finishing steps. However, increase of wettability and surface adhesion by plasma in tropical woods should be better understood due to the natural variability and intrinsic characteristics of each species, such as roughness and wood anatomy. 


\section{CONCLUSIONS}

Increase of wettability of the wood flooring samples depended on glow discharge times. Plasma treatment for $15 \mathrm{~s}$ was sufficient to decrease significantly the wettability, producing the same effect of $45 \mathrm{~s}$ discharge time on wettability. Lapacho wood flooring was less sensitive to plasma treatment, presenting a more stable behavior as a function of time after water droplet deposition. This may be related to the characteristics of the extractives present on lapacho wood surface. Plasma treatment on rode locus wood flooring resulted in full spreading of water droplets.

\section{ACKNOWLEDGMENTS}

We thank the National Counsel for Technological and Scientific Development (CNPq, grant number 141260/2013-0), National Hardwood Flooring Association (ANPM) and the International Tropical Timber Organization (ITTO) for supporting this work.

\section{REFERENCES}

Acda, M.N.; Devera, E.E.; Cabangon, R.J.; Ramos, H.J. 2012. Effects of plasma modification on adhesion properties of wood. International Journal of Adhesion and Adhesives 32(0):70-75.

Akgül, M.; Korkut, S.; Çamlibel, O.; Candan, Z.; Akbulut, T. 2012. Wettability and surface roughness characteristics of medium density fiberboard panels from rhododendron (Rhododendron ponticum) biomass. Maderas-Cienc Tecnol 14(2):185-193.

Asandulesa, M.; Topala, I.; Dumitrascu, N. 2010. Effect of helium DBD plasma treatment on the surface of wood samples. Holzforschung 64(2):223-227.

Avramidis, G.; Klarhöfer, L.; Maus-Friedrichs, W.; Militz, H.; Viöl, W. 2012. Influence of air plasma treatment at atmospheric pressure on wood extractives. Polymer Degradation and Stability 97(3):469-471.

Avramidis, G.; Militz, H.; Avar, I.; Viöl, W.; Wolkenhauer, A. 2012. Improved absorption characteristics of thermally modified beech veneer produced by plasma treatment. European Journal of Wood and Wood Products 70(5):545-549.

Aydin, I.; Demirkir, C. 2010. Activation of Spruce Wood Surfaces by Plasma Treatment After Long Terms of Natural Surface Inactivation. Plasma Chemistry and Plasma Processing 30(5):697-706.

Cademartori, P.H.G.; Muniz, G.I.B.; Magalhães, W.L.E. 2015. Changes of wettability of medium density fiberboard (MDF) treated with He-DBD plasma. Holzforschung 69(2):187-192.

Carlotti, S.; Mas, A. 1998. Improvement of adhesion of PET fibers to rubber by argon-oxygen plasma treatment. Journal of Applied Polymer Science 69(12):2321-2330.

Chandra, S.; Di Marzo, M.; Qiao, Y.M.; Tartarini, P. 1996. Effect of liquid-solid contact angle on droplet evaporation. Fire Safety Journal 27(2):141-158.

Christiansen, A.W. 1991. How overdrying wood reduces its bonding to phenol-formaldehyde adhesives : a critical review of the literature. Part II, Chemical reactions. Wood and Fiber Science 23(1):69-84. 
D'agostino, R.; Favia, P.; Kawai, Y.; Ikegami, H.; Sato, N.; Arefi-Khonsari, F. 2008. Advanced Plasma Technology. Wiley-VCH Verlag GmbH \& Co. KGaA, Weinheim.

Denes, A.R.; Tshabalala, M.A.; Rowell, R.; Denes, F.; Young, R.A. 1999. HexamethyldisiloxanePlasma Coating of Wood Surfaces for Creating Water Repellent Characteristics. Holzforschung 53 (3): 318-326.

Dineff, P.; Gospodinova, D.; Avramov, I. 2011. Plasma aided flame retardation of wood, wooden products and cellulosic materials. Advances in Materials Sciences 11 (3): 28-42.

Fujimoto, H.; Ogino, T.; Takuda, H.; Hatta, N. 2001. Collision of a droplet with a hemispherical static droplet on a solid. International Journal of Multiphase Flow 27(7):1227-1245.

Hünnekens, B.; Peters, F.; Avramidis, G.; Krause, A.; Militz, H.; Viöl, W. 2016. Plasma treatment of wood-polymer composites: a comparison of three different discharge types and their effect on surface properties. Journal of Applied Polymer Science DOI: 10.1002/app.43376.

International Tropical Timber Organization, I. 2015. Bienal review and assesment of the world timber situation 2013-2014. International Tropical Timber Organization, Yokohama, Japan.

Jamali, A.; Evans, P. 2011. Etching of wood surfaces by glow discharge plasma. Wood Science and Technology 45(1):169-182.

Kannangara, D.; Shen, W. 2008. Roughness effects of cellulose and paper substrates on water drop impact and recoil. Colloids and Surfaces A: Physicochemical and Engineering Aspects 330(23):151-160.

Liston, E.M. 1989. Plasma Treatment for Improved Bonding: A Review. The Journal of Adhesion 30(1-4):199-218.

Novák, I.; Popelka, A.; Špitalský, Z.; Mičušík, M.; Omastová, M.; Valentin, M.; Sedliačik, J.; Janigová, I.; Kleinová, A.; Šlouf, M. 2015. Investigation of beech wood modified by radio-frequency discharge plasma. Vacuum 119(0):88-94.

Placinta, G.; Arefi-Khonsari, F.; Gheorghiu, M.; Amouroux, J.; Popa, G. 1997. Surface properties and the stability of poly(ethylene terephtalate) films treated in plasmas of helium-oxygen mixtures. Journal of Applied Polymer Science 66(7):1367-1375.

Potočňáková, L.; Hnilica, J.; Kudrle, V. 2013. Increase of wettability of soft- and hardwoods using microwave plasma. International Journal of Adhesion and Adhesives 45: 125-131.

Riedl, B.; Angel, C.; Prégent, J.; Blanchet, P.; Stafford, L. 2014. Effect of wood surface modification by atmospheric pressure plasma on waterborne coating adhesion. Bioresources 9(3):49084923.

Romagnoli, M.; Segoloni, E.; Luna, M.; Margaritelli, A.; Gatti, M.; Santamaria, U.; Vinciguerra, V. 2013. Wood colour in Lapacho (Tabebuia serratifolia): chemical composition and industrial implications. Wood Science and Technology 47(4):701-716.

Tang, L.; Zhang, R.; Zhou, X.; Pan, M.; Chen, M.; Yang, X.; Zhou, P.; Chen, Z. 2012. Dynamic adhesive wettability of poplar venner with cold oxygen plasma treatment. Bioresources 7(3):3327-3339. 
Thenepalli, T.; Jun, A.Y.; Han, C.; Ramakrishna, C.; Ahn, J.W. 2015. A strategy of precipitated calcium carbonate $\left(\mathrm{CaCO}_{3}\right)$ fillers for enhancing the mechanical properties of polypropylene polymers. Korean Journal of Chemical Engineering 32(6):1009-1022.

Wang, X.S.; Zhao, X.D.; Zhang, Y.; Cai, X.; Gu, R.; Xu, H.L. 2009. Experimental study on the interaction of a water drop impacting on hot liquid surfaces. Journal of Fire Sciences 27(6):545-559. 